\title{
Motivational Aspect of Good Governance
}

\author{
SYED TAHIR HIJAZI
}

\section{INTRODUCTION}

A government job is what most job seekers look for in Pakistan. With a feudal background and job culture inherited from British India, government jobs are believed to provide security, permanency, status and privileged treatment in day to day affairs. But where entering into government jobs is attractive, working in a government atmosphere is often found to be boring, monotonous, and devoid of enthusiasm. Attending office is a matter of killing time. One comes late and leaves early. There is no incentive to work hard, as promotions and benefits depend on seniority not on performance. Coercion seems to be the only management technique, which at times fails or fires back if the manager is not very tactful. Management theories and motivational concepts are foreign names in government departments. Without including the motivational aspects of good governance it would be futile to try to improve performance.

\section{METHODOLOGY}

Good governance can be achieved by recognising the status of the employee. It can be termed as governance by objectives (GBO). It is followed by reviewing motivational theories and trying to find the link between good governance and motivation.

\section{GOVERNANCE BY OBJECTIVE}

The goal-setting theory has an impressive base of research support. But as a government servant responsible for bringing improvement in performance, how do you make goal setting operational? The best answer to this question is that by installing the governance by objectives (GBO) programme. Governance by

Syed Tahir Hijazi is currently Dean, Business Administration, Mohammad Ali Jinnah University, Islamabad Campus. 
objectives emphasises participatively determined goals that are tangible, verifiable and measurable. It is not a new idea. Peter Drucker originally proposed using goals to motivate people rather than to control them more than 40 years ago. Today, no introduction to basic management concepts would be complete without a discussion of Management by objectives.

GBO's appeal undoubtedly lies in its emphasis on converting overall organisational objectives into specific objectives for organisational units and individual members. GBO operationalises the concept of objectives by devising a process by which objectives cascade down through the organisation. The organisation's overall objectives are translated into specific objectives for each succeeding level (that is, divisional departmental, individual) in the organisation. But because lower unit managers jointly participate in setting their own goals, GBO works from the "bottom up" as well as from the objectives at one level to those at the next level. And for the individual government employee, GBO provides specific personal performance objectives.

There are four ingredients common to GBO programmes as can be followed from MBO. These are goal specificity, participative decision-making, an explicit time period, and performance feedback.

The objectives in GBO should be concise statements of expected accomplishments. It is not adequate, for example, to merely state a desire to cut costs, improve service, or increase quality. Such desires have to be converted into tangible objectives that can be measured and evaluated. To cut departmental costs by 7 percent, to improve service by ensuring that all telephone orders are processed within 24 hours of receipt, or to increase quality by keeping returns to less than 1 percent of sales are examples of specific objectives.

The objectives in GBO are not unilaterally set by the boss and then assigned to subordinates. GBO replaces imposed goals with participatively determined goals. The superior and subordinate jointly choose the goals and agree on how they will be measured. Each objective has a specific time period in which it is to be completed. Typically the time period is three months, six months, or a year. So managers and subordinates have specific objectives and stipulated time periods in which to accomplish them.

The final ingredient in a GBO programme is feedback on performance. GBO seeks to give continuous feedback on progress towards goals. Ideally, this is accomplished by giving ongoing feedback to individuals so they can monitor and correct their own actions. This is supplemented by periodic managerial evaluations, when progress is reviewed. This applies at the top of the organisation as well as at the bottom. Feedback in terms of output and performance data is provided to let these people know how they are doing. Formal appraisal meetings also take place at which superiors and subordinates can review progress toward goals and further feedback can be provided. To achieve GBO government servants need to be motivated. 


\section{MOTIVATION}

Many people incorrectly view motivation as a personal trait that is, some have it and others don not. In practice, some managers label employees who seem to lack motivation as lazy. Such a label assumes that an individual is always lazy or is lacking motivation. Our knowledge of motivation tells us that this just is not true. What we know is that motivation is the result of the interaction of the individual and the situation. Certainly, individuals differ in their basic motivational drive. But the same employee who is quickly bored when working on a computer in the office may spend hours on his computer at home playing games. So while analysing the concept of motivation, we must keep in mind that the level of motivation varies from person to person and within the same person at different times.

Motivation is the willingness to exert high levels of effort toward organisational goals, conditioned by the effort's ability to satisfy some individual need. In government ministries, departments and offices a task remains pending for day's, months or years or until followed up by senior officials, concerned people or unforeseen needs. It is repeatedly noticed that whereas tax refund cases and policyrelated issues stay pending for ages, an increase in government servant's salaries announced by Government is processed within days and employees get the increase in their first pay after announcement. The simple reason is motivation through selfinterest. While general motivation is concerned with effort toward any goal, we will narrow the focus to organisational goals in order to reflect our singular interest in work-related behaviour in Government. The three key elements in our definition are effort, organisational goals and needs.

The effort element is a measure of intensity. When someone is motivated, he or she tries hard, but high levels of effort are unlikely to lead to favourable jobperformance outcomes unless the effort is channeled in a direction that benefits the organisation. Therefore, we must consider the quality of the effort as well as its intensity. Effort that is directed toward, and consistent with the organisation's goal, is the kind of effort that we should be seeking. In government functioning the direction of effort often contradicts the motivation. Where motivation is control, concentration of power, and some other benefits the organisational goal is toward increased and efficient output reduction in cost and provision benefit to public at large.

A need in our terminology means some internal state that makes certain outcomes appear attractive. An unsatisfied need creates tension that stimulates drives within the individual. These drives generate a search behaviour to find particular goals that, if attained, will satisfy the need and lead to the reduction of tension. Therefore, we can say that motivated employees are in a state of tension. To relieve this tension, they exert effort. The greater the tension, the higher the effort level. If this effort successfully leads to the satisfaction of the need, the tension is reduced. But since we are interested in work behaviour, this tension reduction effort must also 
be directed toward organisational goals. Therefore inherent in our definition of motivation is the requirement that the individual's needs be compatible and consistent with the organisational goals and not counter to its interests. For example, some employees regularly spend a lot of time talking to friends at work to satisfy their social needs. There is effort in that but unproductively directed. Does the government provide any opportunity to reduce this tension in the direction of its goals and objectives? The answer is mostly no. Before we go into this discussion lets review existing motivation theories and their link with government goal setting.

\section{MOTIVATION THEORIES AND THEIR RELATION TO GOVERNMENT SYSTEM}

Three specific theories were formulated overtime, which even though controversial and questionable in terms of validity, are probably still the best known explanations for employee motivation. These are the Hierarchy of Need theory, Theory $\mathrm{X}$ and $\mathrm{Y}$ and the Motivation Hygiene theory. These theories must be understood by practising managers who regularly use these theories and their terminology in explaining employee motivation.

It is probably safe to say that the most well known theory of motivation is Abraham Maslow's hierarchy of needs. Maslow hypothesised that within every human being there exists a hierarchy of five needs. These are:

1. Physiological: Includes hunger, thirst, shelter, sex and other bodily needs.

2. Safety: Includes security and protection from physical and emotional harm.

2. Social: Includes affection, belongingness, acceptance and friendship.

4. Esteem: Includes internal esteem factors such as self-respect autonomy and achievement, and external esteem factors such as status recognition and attention.

5. Self-actualisation: The drive to become what one is capable of becoming includes growth, achieving ones potential and self-fulfillment.

As one of these needs gets substantially satisfied, the next need becomes dominant. Physiological and safety needs according to Maslow are lower needs. If individuals have acquired these needs, they will be looking for higher needs. Maslow said that if you want to motivate someone you need to understand what level of hierarchy that person is. Currently government servants in Pakistan are provided with the lower order needs. To motivate them to perform better their level of hierarchy need to be assessed to know what can motivate them most. The inability of the government management to understand the level of needs and the basic concept of motivation hinders the process of achieving good governance.

Douglas McGregor proposed two distinct views of human beings: one basically negative, labeled Theory X, and the other basically positive, labeled Theory Y. After viewing the way in which managers dealt with employees, McGregor 
concluded that a manager's view of the nature of human beings is based on certain grouping of assumption and that he or she tends to mold his or her behaviour towards subordinates according to these assumptions.

Under theory $\mathrm{X}$, the four assumptions held by managers are:

1. Employees inherently dislike work and whenever possible will attempt to avoid it.

2. Since employees dislike work they must be coerced, controlled, or threatened with punishment to achieve goals.

3. Employees will avoid responsibilities and seek formal direction whenever possible.

4. Most workers place security above all other factors associated with work and display little ambition.

In contrast to these negative views about the nature of human beings, McGregor listed the four positive assumptions that he called Theory Y:

1. Employees can view work as being as natural as rest or play.

2. People will exercise self-direction and self control if they are committed to the objectives.

3. The average person can learn to accept, even seek responsibility.

4. The ability to make innovative decisions is widely dispersed throughout the population and is not necessarily the sole province of those in management positions.

While talking of good governance we need to explore the department of the issue. Unless the employee is motivated enough and his motivation is in line with the objective of the organisation he cannot deliver good governance. Government employees derive great satisfaction from the exercise of power and control over affairs. Sometimes this lies in his inaccessibility which ultimately adversely affects the performance of his department.

\section{SPECIAL ISSUES IN MOTIVATION}

Various groups provide specific challenges in terms of motivation. In this section we look at some of the unique problems faced in trying to motivate professional working in government, contingent workers, the diverse workforce, low-skilled service workers, and people doing highly repetitive tasks.

\section{MOTIVATING PROFESSIONALS}

In contrast to a generation ago, the typical government employee today is more likely to be a highly trained professional with a college degree than a bluecollar factory worker is. These professionals receive intrinsic satisfaction from their work. They tend to be well paid. So what if any special concern should be aware of 
when trying to motivate a team of engineers working at computer bureau. Professionals are typically different from nonprofessionals. They have a strong and long-term commitment to their field of expertise. Their loyalty is more often to their profession than to their employer. To keep current in their field, they need to regularly update their knowledge, and their commitment to their profession means they rarely define their workweek in terms of 8 to 5 or five to six days a week.

What motivates professionals? Money and promotions typically are low on their priority list. Why? They need to be reasonably paid and they enjoy what they do. In contrast, job challenge tends to be ranked high. They like to tackle problems and find solutions. Their chief reward in their job is the work itself. Professionals also value support. They want others to think what they are working on is important. Although this may be true for all employees, because professionals tend to be more focused on their work as their central life interest, nonprofessionals typically have other interests outside of work that can compensate for needs not met on the job.

\section{MOTIVATING THE DIVERSIFIED WORKFORCE}

Not everyone is motivated by money. Not everyone wants a challenging job. Employees who are attending college typically place a high value on flexible work hours, job sharing or temporary assignments. If you are going to maximise your employee's motivation, you have got to understand and respond to this diversity. How? The key word to guide you should be flexibility. Be ready to design work schedules, compensation plans, benefits, physical work settings, and the like to reflect your employees' varied needs. This might include offering child and elder care, flexible work hours and job sharing for employees with family responsibilities. It also might include offering flexible leave policies for immigrants who want occasionally to make extensive return trips to their homelands.

\section{MOTIVATING LOW-SKILLED SERVICE WORKERS}

In Pakistan class four government servants are in abundance. They are the hardest group to motivate. If they realise that their job is firm and they are not going to lose it even if they do not work, they exercise their efforts and shirk work. It is important that such workers are tackled differently. They may be invited to many of the trainings, work recognition awards may be given, and monetary rewards to the best workers.

\section{MOTIVATING PEOPLE DOING HIGHLY REPETITIVE JOBS}

Our final category considers employees who do standardised and repetitive jobs. For instance, working on an assembly line or transcribing court reports are jobs that workers often find boring and even stressful. Motivating individuals in these jobs can be made easier through careful selection. People vary in their tolerance for ambiguity. Many individuals prefer jobs that have a minimal amount of discretion and variety. Such an individual is obviously a better match to standardised jobs that should also be the first considered for automation. 
Some tasks, for instance, are just far more efficiently done on assembly lines than in teams. This leaves limited options. You may not be able to do much more than try to make a bad situation tolerable by creating a pleasant work climate. This might include providing clean and attractive work surroundings, ample work breaks, the opportunity to socialise with colleagues during these breaks, and empathetic supervisors.

\section{SUMMARY AND IMPLICATIONS FOR DECISION-MAKERS}

We have presented a number of motivation theories and applications in this paper. While it's always dangerous to synthesise a large number of complex ideas into a few simple guidelines, the following suggestions summarise the essence of what we know about motivating employees in organisations.

\section{Recognise Individual Differences}

Government employees have different needs. Do not treat them all alike. Moreover, spend the time necessary to understand what's important to each employee. This will allow you to individualise goals, level of involvement and rewards to align with individual needs.

\section{Use Goals and Feed Back}

Government employees should have hard, specific goals, as well as feedback on how well they are faring in pursuit of those goals.

\section{Allow Government Employees to Participate in Decisions That Affect Them}

Government employees can contribute to a number of decisions that affect them: setting work goals, choosing their own benefit packages, solving productivity and quality problems, and the like. This can increase employee productivity, commitment to work goals, motivation, and job satisfaction.

\section{Link Rewards to Performance}

Rewards should be contingent on performance. Importantly, government employees must perceive a clear linkage. Regardless of how closely rewards are actually correlated to performance criteria, if individuals perceive this relationship to be low, the results will be low performance, a decrease in job satisfaction, and increase in turnover and absenteeism statistics.

\section{Check the System for Equity}

Rewards should also be perceived by government employees as equating with the inputs they bring to the job. At a simplistic level, this should mean that 
experience, skills abilities, effort, and other obvious inputs should explain differences in performance and, hence, pay, job assignments and other obvious rewards.

\section{CONCLUSION}

Looking at motivation theories and role of government servants we come to the following conclusions.

The working system in government is administrative and not management. There is no use for motivational theories in the system. Government assignments are not goal oriented, so there is little room for reward and punishment. Governance by Objective (GBO) is the need of the day, where motivation to the individual worker can be provided and improvement can be monitored. Good governance cannot be achieved without taking into consideration the motivation of the key role occupant. 